\title{
A direct comparison of recognition failure rates for recallable names in episodic and semantic memory tests
}

\author{
JAMES H. NEELY and DAVID G. PAYNE \\ Purdue University, West Lafayette, Indiana 47907
}

\begin{abstract}
In an extension of Muter's (1978) research, subjects studied pairs of lowercase cues and uppercase targets consisting of famous names (e.g., betsy ROSS), nonfamous names (e.g., edwin CONWAY), weakly related words (e.g., grasp BABY), and unrelated words (e.g., art GO). Following recognition tests in which surname and word targets were tested in the absence of their cues, cued recall tests for the surname and word targets were given. In semantic recognition and recall tests, the response to a surname was to be made solely on the basis of its fame, regardless of whether or not it had appeared in the study list. In episodic memory tests, the response to a surname was to be made solely on the basis of whether or not it had appeared in the study list, regardless of its fame. In all tests, the response to a nonname was to be made solely on the basis of whether or not it had appeared in the study list. The Tulving-Wiseman (1975) function accurately predicted recognition failure rates for famous surnames, whether or not they were from the study list and whether the test was episodic or semantic, and for targets from the weakly related word pairs. However, recognition failure rates were lower than the Tulving-Wiseman function predicted for nonfamous surnames in the episodic memory test and for targets from unrelated word pairs. Discussion focused on these results' implications for the nature of the Tulving-Wiseman function and the psychological reality of the episodic-semantic memory distinction.
\end{abstract}

According to Tulving (1972), episodic memory tasks require subjects to answer queries about when, where, or under what circumstances they experienced an event, whereas semantic memory tasks require them to answer queries about organized knowledge concerning word meanings and the relations among concepts, independent of the autobiographical context in which that knowledge was gained. Although most researchers accept Tulving's episodic-semantic distinction as a useful taxonomy for classifying different kinds of memory tasks, considerable disagreement centers on whether episodic and semantic memory tasks tap functionally different memory stores and/or retrieval processes (e.g., Anderson \& Ross, 1980; Atkinson, Herrmann, \& Wescourt, 1974; Carroll \& Kirsner, 1982; Herrmann \& Harwood, 1980; Kintsch, 1974; McCloskey \& Santee, 1981; McKoon \& Ratcliff, 1979; Muter, 1978; Shoben, Wescourt, \& Smith, 1978; Tulving, 1976). To begin to address this controversial issue empirically, one can ask whether a variable has similar or dissimilar effects in episodic and semantic memory tasks (Anderson \& Ross, 1980). Too often the answer to this question has been based on a comparison

The research reported here was supported by Grant R01 HD 15054 awarded to the first author by the National Institute of Child Health and Human Development. Portions of this research were reported at the 1981 meeting of the Psychonomic Society in Philadelphia. Requests for reprints should be addressed to James H. Neely, Department of Psychological Sciences, Purdue University, West Lafayette, Indiana 47907. of results from different experiments. But even in those few cases in which variables' effects in episodic and semantic memory tasks have been directly compared in a single experiment, the episodic and semantic memory tasks have differed in whether or not they were preceded by subjects' having studied items in anticipation of an episodic memory test (Shoben et al., 1978) or have differed in the items and/or conditions that appeared in them (McKoon \& Ratcliff, 1979, Experiments 1-3 vs. Experiment 4; Shoben et al., 1978).

What is needed, then, are direct comparisons of variables' effects on performance in episodic and semantic memory tests that equate all other variables except those needed to distinguish the two types of tests. As far as we know, only one published study has made such comparisons (i.e., Carroll \& Kirsner, 1982). For present purposes, the most interesting aspect of Carroll and Kirsner's (1982) results was that episodic recognition decisions about two words in a test pair were faster and more accurate if those two words had been paired together in the first phase of the experiment than if they had not. On the other hand, lexical decisions about two words in a test pair were unaffected by this variable. As Carroll and Kirsner noted, their finding that the similarity of the encoding context and the memory test context had a large effect in episodic memory is analogous to what Tulving and Thomson (1973) have called the encoding specificity effect in episodic memory. Their results extend Tulving and Thomson's results by 
showing that the large encoding specificity effects obtained in an episodic memory test do not occur in a semantic memory test equated with the episodic memory test on all variables other than the nature of the test.

Another paradigm that yields an encoding specificity effect in episodic memory is the recognition failure paradigm (Tulving \& Thomson, 1973). In this paradigm, subjects first study a capitalized target word in the context of a weakly associated lowercase cue word (e.g., ground COLD), expecting that the lowercase cue word will subsequently be given as a cue for recall of the capitalized target word. In an unexpected recognition test typically given before the expected cued recall test, subjects are often unable to recognize a target item presented by itself or in the context of other distractor items, even though they are later able to recall it in the presence of the cue it appeared with during study. This particular encoding specificity effect has been termed "recognition failure of recallable words" and will hereafter be referred to simply as recognition failure (RF).

Flexser and Tulving (1978) and Tulving and Wiseman (1975) have shown that RF in each of a large number of episodic memory experiments can be successfully predicted by the following quadratic equation:

$$
\mathrm{PRF}=1-\left[\mathrm{RN}+.5\left(\mathrm{RN}-\mathrm{RN}^{2}\right)\right],
$$

where PRF is the predicted probability of RF, and RN is the observed overall probability of recognition in the condition of interest. In fact, the success of the TulvingWiseman (1975) function (hereafter abbreviated TWF) in predicting RF is now so well documented that a number of recent studies have been aimed at delineating the study and testing conditions under which one obtains data that deviate significantly from its predictions (e.g., Bartling \& Thompson, 1977; Begg, 1979; Gardiner \& Tulving, 1980).

To determine if RF occurs only in episodic memory tests, Muter (1978) examined RF in a semantic memory test. Subjects were first presented a list of surnames (e.g., ROSS, ASH) and asked to indicate which ones they recognized as being names of historical figures. Next, they were given a list of brief character descriptions plus first names (e.g., maker of the U.S. flag; BETSY) and asked to recall the famous surname that corresponded to each of these cues. On the basis of their overall recognition rates, Muter divided the target surnames into quartiles and found that RF for these quartiles did not differ significantly from that predicted by the TWF. Since Muter's data suggested that retrieval is context dependent to the same degree in episodic and semantic memory tasks, a result seemingly at odds with Carroll and Kirsner's (1982) results at a conceptual level, Muter (and Anderson \& Ross, 1980, p. 446) used these data to argue against the psychological reality of the episodic-semantic memory distinction.

Unfortunately, there are both empirical and methodological problems associated with Muter's (1978) experiment. The empirical problem is that, while Muter's quartile RF rates did not deviate significantly from the TWF, the overall RF rate of .535 based on all items was significantly lower $(p<.01$, by a two-tailed binomial test) than the RF of .602 predicted by the TWF on the basis of the overall recognition rate of 294 (see Muter, 1978, Table 2). Hence, contrary to his quartile data, Muter's overall data indicate that the RF rate obtained in semantic memory is different from that which the TWF predicts for episodic memory. The methodological problem is that Muter's conclusion that RF rates are similar in episodic and semantic memory tests was based on data from experiments having different procedures. That is, unlike subjects in episodic memory experiments concerned with RF, Muter's subjects did not encode the famous surnames in the context of their first names in anticipation of a cued recall test. Furthermore, since RF has not been examined for famous names in episodic memory tests, the TWF may not be able to predict RF accurately for famous names even when they are tested in an episodic memory test.

The present experiment directly compares RF in episodic and semantic memory tests equated on all variables other than the instructions describing the memory tests. This was accomplished using the procedures outlined in Table 1. To familiarize them with the general procedures, all subjects were first given a practice list containing 12 weakly related and 12 unrelated cue-target pairs and then were given a cued recall test for the targets. Following the practice test, the episodic and semantic memory groups both studied the same critical list containing 12 weakly related and 12 unrelated word pairs along with 24 name "pairs" each consisting of a first-name (or first-plus-middle-name) cue and a surname target. Twelve of these name pairs were famous names and 12 were nonfamous names. Separate episodic and semantic memory groups received four tests on the critical list: an episodic recognition test on the nonname items, an episodic or a semantic recognition test (depending on the group) on the surname items, an episodic cued recall test on the nonname items, and an episodic or a semantic cued recall test (depending on the group) on the surname items. Exactly the same items appeared on the tests given to the episodic and semantic memory groups. The sole distinction between the groups was the instructions they were given as to how they were to respond on the two tests involving names.

To understand how subjects were to respond in the episodic and semantic name-memory tests, consider a two-item study list containing the famous name BETSY ROSS and the nonfamous name EDWIN CONWAY. The episodic and semantic recognition tests were identical and contained ROSS, CONWAY, COOPER, and FERGUSON. ROSS and CONWAY appeared on the study list and COOPER and FERGUSON did not. ROSS and COOPER are famous names, whereas CONWAY and FERGUSON are not. (For those readers experiencing RF, the recall cue for COOPER would be James Fenimore.) "Yes" and "no" were the correct responses the same number of times in each type of 
recognition test. Because episodic memory subjects were to respond "yes" to a famous name (ROSS) and a nonfamous name (CONWAY) and "no" to a famous name (COOPER) and a nonfamous name (FERGUSON), they could correctly respond to a name only on the basis of whether or not it had appeared in the study list and not on the basis of its fame. Likewise, since semantic memory subjects were to respond "yes" to a famous name from the study list (ROSS) as well as one not from the study list (COOPER) and "no" to a nonfamous name from the study list (CONWAY) and one not from the study list (FERGUSON), they could correctly respond to a name only on the basis of its fame and not on the basis of whether or not it had appeared in the study list.

The design of this experiment permits an answer to four questions: (1) Can the TWF accurately predict semantic RF for the condition most analogous to that of Muter (1978), that is, for the famous names not from the study list? If so, Muter's quartile data would be replicated and extended to conditions in which there has been recent prior episodic study of other "extraneous" names. If not, the results would replicate Muter's overall data, thereby demonstrating the limited generality of his quartile data. (2) Can the TWF accurately predict both semantic and episodic RF of the famous names from the study list? If so, the results would support Muter's conciusion that retrieval from episodic and semantic memory are equally context dependent. Alternatively, if the TWF accurately predicts RF of the famous names from the study list for the episodic test but not for the semantic test, the results would challenge

Table 1

Summary of Design of the Experiment

\begin{tabular}{cccc}
\hline & & & Subject's Response in \\
Subject's & Materials & Example of & Semantic \\
Task & Employed & Episodic \\
\hline
\end{tabular}

Practice List

\begin{tabular}{|c|c|}
\hline Study Practice List & $\begin{array}{l}12 \text { weakly associated cue-target pairs } \\
12 \text { unrelated cue-target pairs }\end{array}$ \\
\hline Cued Recall Test & 24 cues presented in practice list \\
\hline Study Critical List & $\begin{array}{l}12 \text { weakly associated cue-target pairs } \\
12 \text { unrelated cue-target pairs } \\
12 \text { famous cue-target name pairs } \\
12 \text { nonfamous cue-target name pairs }\end{array}$ \\
\hline \multicolumn{2}{|l|}{ Critical List Tests } \\
\hline Nonname Recognition & $\begin{array}{l}12 \text { related targets } \\
12 \text { unrelated targets } \\
24 \text { lures }\end{array}$ \\
\hline Name Recognition & $\begin{array}{l}12 \text { famous surnames presented in list } \\
12 \text { famous surnames not presented } \\
\text { in list } \\
12 \text { nonfamous surnames presented } \\
\text { in list } \\
12 \text { nonfamous surnames not } \\
\text { presented in list }\end{array}$ \\
\hline Nonname Cued Recall & $\begin{array}{l}12 \text { related cues from critical list } \\
12 \text { unrelated cues from critical list }\end{array}$ \\
\hline Name Cued Recall & $\begin{array}{l}12 \text { cues for famous names presented } \\
\text { in list } \\
12 \text { cues for famous names not } \\
\text { presented in list } \\
12 \text { cues for nonfamous names } \\
\text { presented in list } \\
12 \text { cues for nonfamous names not } \\
\text { presented in list }\end{array}$ \\
\hline
\end{tabular}

ground-COLD

glue-FOOD

$\begin{array}{lll}\text { ground } & \text { COLD* } & \text { COLD } \\ \text { glue } & \text { FOOD } & \text { FOOD }\end{array}$

Critical List
think-STUPID
blade-RUG
betsy-ROSS
edwin-CONWAY

STUPID
RUG
FLOWER
ROSS
COOPER
CONWAY
PETERS
think
blade
Maker of U.S. flag;
Betsy
Author of Last of the Mohicans;
James Fenimore
British philosopher and essayist;
Edwin
American inventor of fluorescent
lighting; Melvin .

$\begin{array}{ll}\text { YES } \dagger & \text { YES } \\ \text { YES } & \text { YES } \\ \text { NO } & \text { NO } \\ \text { YES } & \text { YES } \\ \text { YES } & \text { NO } \\ \text { NO } & \text { YES } \\ \text { NO } & \text { NO } \\ \text { STUPID } & \text { STUPID } \\ \text { RUG } & \text { RUG } \\ \text { ROSS } & \text { ROSS }\end{array}$

COOPER

CONWAY

\footnotetext{
*The practice list cued recall and the nonname cued recall and recognition tests were episodic memory tests for both the semantic and episodic groups; therefore, the responses are identical for both groups. fFor the nonname recognition test and the episodic name recognition test, a "yes" response indicates that the item was a list item and a "no" response indicates that the item was not a list item. For the semantic recognition test, a "yes" response indicates that the item is a famous name and a "no" response indicates that the item is a nonfamous name.
} 
Muter's conclusion that retrieval from episodic and semantic memory are equally context dependent and would extend the generality of Carroll and Kirsner's (1982) finding that episodic memory and semantic memory are not equally context dependent. (3) Can the TWF accurately predict semantic RF of famous names when the names have and have not appeared in the study list? If so, one would conclude that recent episodic study of famous names does not affect how well the TWF predicts their RF rate in a semantic memory task. If, on the other hand, the TWF accurately predicts both episodic and semantic RF of famous names from the study list but not semantic RF of famous names not from the study list, this would indicate that the crucial variable for determining the accuracy of the TWF's predictions is not whether episodic or semantic information is being queried, but rather, whether the target items in the memory test have been recently studied. (4) Can the TWF accurately predict RF of word targets from unrelated and weakly related pairs? Wiseman and Tulving (1976) found that although cued recall performance was much better when targets appeared in weakly related pairs rather than in unrelated pairs, $\mathrm{RF}$ of targets from these two types of pairs was equivalent and accurately predicted by the TWF. (This was so because the relatedness manipulation had little effect on overall recognition, from which RF is predicted.) The present experiment also permits a determination of the effects of cue-target relatedness on episodic RF by including weakly related and unrelated nonname pairs and famous (strongly related) and nonfamous (unrelated) name "pairs" in the study list.

\section{METHOD}

\section{Subjects}

Ninety-six undergraduate introductory psychology students participating in partial fulfillment of a course requirement for research participation or library research were tested in four groups of 23-25 each.

\section{Materials}

Thirteen of the 24 famous names were taken directly from Muter (1978) and 11 were selected using criteria very similar to Muter's. Specifically, we selected 11 names of people listed in Webster's New Collegiate Dictionary (1976) who in our estimation achieved fame prior to 1950 . Also, the dictionary listed no other persons with the same surname that the authors recognized as being famous and each surname filled at least half a column in each of three telephone directories for Chicago suburbs.

The 24 nonfamous surnames appeared in the telephone directories with frequencies approximately equal to those of the famous surnames, and none of them appeared in the dictionary as a person recognized by the authors as being famous. The first, or first-plus-middle, names (hereafter called first names) and fictitious character descriptions for the nonfamous names were generated by the second author. The famous and nonfamous first names and surnames are listed in the appendix, along with the brief character descriptions and first names that appeared as cues in the cued recall tests.

The nonname items were 48 weakly associated cue-target word pairs selected from Tulving and Thomson (1973). When the nonname cue and target items served as related pairs, they were the weak associates taken from Tulving and Thomson's list. When they served as unrelated pairs, the target words were re-paired with the cue items from other weakly associated pairs so as to avoid any obvious association.

Two critical lists (List A and List B) were constructed such that a nonname target item that served in a related cue-target pair in List A served in an unrelated pair in List B, and vice versa. Also, the half of the famous and nonfamous names that were randomly assigned to be study items in List A served as lures for List $B$ and vice versa. The presentation order of the four types of items appearing in the critical list (see Table 1) was randomly determined for List A and maintained for List B.

Each uppercase name and nonname target item was typed and centered on a slide along with its associated lowercase cue word(s), which appeared above and offset to the left of it. The practice list cued recall test and the four critical list tests were prepared as separate pages in booklet form. The cued recall test for the practice list consisted of a random ordering of the 24 cue words presented in the practice list.

The nonname recognition test consisted of the 24 targets presented in the critical study list and 24 lures. The lure item for each target was an associate generated by the second author in response to Tulving and Thomson's (1973) free association cue for that target (e.g., SPRING was the lure generated in response to the free association cue BLOOM for the target word FLOWER). The name recognition test contained all 24 famous and 24 nonfamous names. Half of each of these item types had been presented in List A and the remaining half in List B. Thus, for individual subjects, half of the famous and nonfamous names were from the study list and half were not.

The nonname cued recall test consisted of the 24 cues presented in the critical study list. For individual subjects, 12 of these 24 cues had been presented in related pairs and 12 had been presented in unrelated pairs. The name cued recall test contained a random ordering of all 48 (24 famous and 24 nonfamous) character descriptions plus first names. (See appendix.) Half of each of these cues corresponded to names presented in List $A$, and half correponded to names presented in List B. Thus, for individual subjects, half each of the famous and nonfamous name cues were from the study list and half were not. The cues for the names presented in List A appeared on one page and cues for the names presented in List B appeared on another page, with the cues for the famous and nonfamous names randomly distributed on each page of the test.

\section{Procedure}

Separate groups of subjects were tested in one of the four possible study-test conditions formed by factorially crossing two critical lists (Lists A and B) with two types of name retention tests (episodic and semantic). The practice and critical study lists were presented at a 5 -sec rate for all subjects.

Before the practice list, subjects were informed they would be shown 24 slides, each containing one word in capital letters and one word in lowercase letters. An example slide was shown, and subjects were told that their task was to try to remember the words in capital letters (i.e., target words), but that they should also pay attention to the words in lowercase letters (i.e., cue words), since these words might help them to remember the capitalized words. After the practice list items were presented in a random order, subjects were given instructions for the cued recall test and were allowed 3 min to complete it.

Following the practice list test, subjects were told that the second list contained 48 slides and that half of the slides (nonname items) would be similar to the ones presented in the first list, whereas the remaining half of the slides contained the names of real or fictitious people. With respect to the slides containing names, subjects were told that their memory for the surnames would be tested and were told that the first name(s) in the 
lowercase letters might help them to remember the capitalized surnames. However, they were not informed of the specific type of name-item retention test they would be given.

After critical list presentation, subjects were informed that they would be given four separate memory tests for the items they had just studied. Subjects were given $5 \mathrm{~min}$ to complete each test, with a warning being given when 1 min remained. Because the first and third critical list tests involving nonnames were the same for the episodic and semantic groups, we will describe these nonname tests first.

For the nonname recognition test, subjects were instructed to circle a $\mathrm{Y}$ alongside an item if they thought that the item had appeared in the list just studied, or to circle an $N$ if they thought it had not. Subjects were also told to indicate how confident they were of their yes/no answers by circling a 1 if they were "only guessing," a 2 if they were "fairly certain," or a 3 if they were "absolutely certain" of their answer. This confidence rating scale was also used in the name recognition tests.

The nonname cued recall test instructions told subjects to write down all of the capitalized words (i.e., targets) that they could remember from the study list. Each target word was to be written alongside the cue word with which it had been presented at study. If subjects were able to recall a target item but were not able to remember which cue word it appeared with in the study list, then they were to write that target word off to the side of the test sheet.

For the name recognition test, episodic subjects were instructed to circle a $\mathrm{Y}$ if they believed the surname on the test sheet had appeared in the study list or circle an $N$ if they felt it had not. For the name cued recall test, they were told to write down beside each of the first names that had appeared in the list the surname that had been presented with it in the list. They were also told that if they were not able to recall the surname when they read a first name, they could read the description presented along with that first name as a further retrieval cue. It was emphasized that if the description made the subject think of a surname that was not presented in the slides, then that surname was not to be written down.

For the name recognition test, semantic subjects were instructed to base their answers on whether they recognized the surnames as being the names of people who achieved fame prior to 1950. Encircling $Y$ meant the subject thought the surname met this definition of fame, whereas encircling $N$ meant that the subject thought it did not. It was emphasized that if the subjects recognized a surname as being one that appeared in the study list but not as being famous, then $\mathrm{N}$ was to be circled. For the name cued recall test, instructions told semantic subjects to write down beside a first-name-plus-description cue the famous surname associated with that cue. Once again, it was emphasized that recall was not to be limited to only those famous surnames presented in the study list and that if a surname from the study list was not famous it should not be written down.

\section{RESULTS AND DISCUSSION}

\section{Scoring}

In all cued recall tests, subjects were given credit for correctly recalling a target item even if it was not written beside its cue, which happened only rarely. In all recognition tests, hits and false alarms were $\mathrm{Y}$ responses associated with a confidence rating of either 2 or $3 .^{1}$

\section{Name Tests}

For the semantic group, false alarms and cued recall intrusions for the famous names from and not from the study list were false positive recognitions and intrusions of nonfamous names from and not from the study list, respectively. For the episodic group, false alarms and cued recall instrusions for the famous names and nonfamous names were, respectively, false positive recognitions and intrusions of famous names and nonfamous names not from the study list.

Overall cued recall and recognition performance. Table 2 displays recognition and cued recall performance on the name items for the episodic and semantic groups. A 2 (list: A vs. B) by 2 (item type: names on list vs. names not on list for the semantic group; famous names vs. nonfamous names for the episodic group) by 2 (retention test: correct cued recall vs. recognition hits) mixed-factor analysis of variance was performed on the data from the semantic group and from the episodic group. Unless otherwise noted, all effects called statistically significant had $p$ values $<.05$.

For the semantic group, both correct cued recall and recognition hit rates were higher for famous names from the study list than for famous names not from the study list $[\mathrm{F}(1,47)=94.8, \mathrm{MSe}=.020]$. However, the magnitude of this effect was different for the two study lists $[F(1,47)=10.5, \mathrm{MSe}=.020$, for the List by Item Type interaction]. Also, for the famous names from the study list, correct cued recall performance was equal to recognition hit performance, whereas for the famous names not from the study list, correct cued recall performance was much higher $[F(1,47)=10.9, \mathrm{MSe}=.015$, for the Item Type by Retention Test interaction] but only for one of the study lists $[\mathrm{F}(1,47)=10.8, \mathrm{MSe}=.015$,

Table 2

Proportions of Recognition Hits, False Alarms, Correct Cued Recall, and Cued Recall Intrusions for the Name Items

\begin{tabular}{|c|c|c|c|c|}
\hline Item Type & $\begin{array}{c}\text { Recognition } \\
\text { Hits }\end{array}$ & $\begin{array}{c}\text { False } \\
\text { Alarms }\end{array}$ & $\begin{array}{c}\text { Correct Cued } \\
\text { Recall }\end{array}$ & $\begin{array}{l}\text { Cued Recall } \\
\text { Intrusions }\end{array}$ \\
\hline & \multicolumn{4}{|c|}{ Semantic Group } \\
\hline Famous Names From Study List & .68 & .34 & .66 & .08 \\
\hline \multirow[t]{2}{*}{ Famous Names Not From Study List } & .43 & .18 & .52 & .16 \\
\hline & \multicolumn{4}{|c|}{ Episodic Group } \\
\hline Famous Names From Study List & .77 & .22 & .60 & .13 \\
\hline Nonfamous Names From Study List & .71 & .12 & .12 & .08 \\
\hline
\end{tabular}

Note-See the text for a description of the items constituting false alarms fand cued recall intrusions) for each of the groups and item types. 
for the List by Item Type by Retention Test interaction]. However, the fact that recognition hit rate was as high as the correct cued recall rate for the famous names from the study list should be viewed with caution, since the false alarm rate for these items was also rather high.

In the episodic group for both the famous and nonfamous names from the study list, subjects had a higher proportion of recognition hits than correct cued recalls $[F(1,45)=375.5, \mathrm{MSe}=.018]$. Also, performance was far better for "related" famous names than for "unrelated" nonfamous names $[\mathrm{F}(1,45)=229.5, \mathrm{MSe}=.015]$. However, this "relatedness" effect was larger for correct cued recall than for recognition hits $[F(1,45)=160.6$, $\mathrm{MSe}=.013]$, a finding both similar and dissimilar to results reported by Wiseman and Tulving (1976). Using nonname cue-target items, Wiseman and Tulving also found that cue-target relatedness had a much larger effect on cued recall than on recognition. However, in their study, cued recall was actually better than recognition for targets from related pairs, whereas the opposite was true for targets from unrelated pairs. In the present study, however, the recognition hit rate exceeded the correct cued recall rate for both the "unrelated" nonfamous names and the "related" famous names. The only other significant effect was the effect of list $[\mathrm{F}(1,45)=5.40, \mathrm{MSe}=.042]$.

Recognition failure. A 2 by 2 (recalled/not recalled by recognized/not recognized) contingency table was constructed for each subject for each of the various target item types he or she was tested on. The first four columns of Table 3 contain these contingency tables aggregated across subjects. To illustrate how the observed RF rate and the RF rate predicted by the TWF were computed, we first consider the aggregate data for the famous names from the study list for the semantic group. Of the $389(314+75)$ items recalled, 75 were not recognized, for an observed $R F$ rate of $75 \div 389=.193$. Replacing RN in Equation 1 with the overall recognition rate of .685 [i.e., $(314+87) \div(314+87+75+109)$ ], the TWF predicts an RF rate of .207. For this aggregate analysis, we followed Muter (1978) and used the binomial distribution to evaluate the statistical significance of the deviation of the observed RF rate from the predicted RF rate. ${ }^{2}$ The fifth and six th columns of Table 3 give the observed and predicted RF rates for the aggregate data, along with an indication of statistical significance. (Because the underlying binomial distributions were not symmetrical, to obtain a "two-tailed" $p$ value, we multiplied the computed one-tailed $p$ value by 2 .)

Since RF rates for different items of a particular type may not be independent for a particular subject, the independence assumption underlying the foregoing binomial distribution analysis may have been violated. Therefore, in an additional analysis, we used individual subjects, rather than individual items, as our unit of analysis. ${ }^{3}$ For each subject, we computed an observed and a predicted RF rate for each of the various item types using the computational procedures described earlier. When a subject recalled no items of a particular item type, RF could not be computed (because the denominator would be 0 ) and the data for that particular item type for that particular subject were ignored. A sign test was used to determine if the number of subjects whose observed RF fell above or below the predicted RF was statistically greater than expected by chance. The seventh and eighth columns of Table 3 give the observed and predicted RF rates averaged across the individual subjects. Since the observed RF fell below the predicted RF whenever these two values were significantly different, the ninth column gives the num. ber of subjects, out of the total number of subjects who provided data for that item type, whose RF rates fell below the predicted RF rates, along with an indication of statistical significance.

There are three noteworthy aspects of the RF data presented in Table 3. First, consider the RF rates for the items that most closely replicate Muter (1978), that is, the RF rates in the semantic memory test for the famous names not from the study list. In addition to the analyses

Table 3

A 2 by 2 Cassification of the Recall and Recognition of the Name Items, Along With the Aggregate and Individual Subject Observed and Predicted Recognition Failure (RF) Rates

\begin{tabular}{|c|c|c|c|c|c|c|c|c|c|}
\hline \multirow[b]{2}{*}{ Item Type } & \multicolumn{2}{|c|}{ Recognized } & \multicolumn{2}{|c|}{ Not Recognized } & \multicolumn{2}{|c|}{ Aggregate Data } & \multicolumn{2}{|c|}{$\begin{array}{c}\text { Individual } \\
\text { Subject Data }\end{array}$} & \multirow[b]{2}{*}{$\# \mathrm{O}<\mathrm{P} \dagger$} \\
\hline & Recalled & $\begin{array}{c}\text { Not } \\
\text { Recalled }\end{array}$ & Recalled & $\begin{array}{c}\text { Not } \\
\text { Recalled }\end{array}$ & $\begin{array}{c}\text { Observed } \\
\text { RF }\end{array}$ & $\begin{array}{l}\text { Pre- } \\
\text { dicted RF }\end{array}$ & $\begin{array}{c}\text { Observed } \\
\text { RF }\end{array}$ & $\begin{array}{c}\text { Pre- } \\
\text { dicted RF }\end{array}$ & \\
\hline & \multicolumn{9}{|c|}{ Semantic Group $(N=49)$} \\
\hline \multirow[t]{2}{*}{$\begin{array}{l}\text { Famous Names in List } \\
\text { Famous Names Not in List }\end{array}$} & $\begin{array}{l}314 \\
180\end{array}$ & $\begin{array}{l}87 \\
72\end{array}$ & $\begin{array}{r}75 \\
123\end{array}$ & $\begin{array}{l}109 \\
205\end{array}$ & $\begin{array}{l}.20 \\
.41\end{array}$ & $\begin{array}{l}.21 \\
.44\end{array}$ & $\begin{array}{l}.19 \\
.40\end{array}$ & $\begin{array}{l}.22 \\
.46\end{array}$ & $\begin{array}{l}27 / 46 \\
27 / 46\end{array}$ \\
\hline & \multicolumn{9}{|c|}{ Episodic Group $(\mathrm{N}=47)$} \\
\hline $\begin{array}{l}\text { Famous Names in List } \\
\text { Nonfamous Names in List }\end{array}$ & $\begin{array}{r}283 \\
61\end{array}$ & $\begin{array}{l}146 \\
335\end{array}$ & $\begin{array}{r}52 \\
3\end{array}$ & $\begin{array}{r}78 \\
158\end{array}$ & $\begin{array}{l}.15 \\
.05^{*}\end{array}$ & $\begin{array}{l}.14 \\
.19\end{array}$ & $\begin{array}{l}.16 \\
.07\end{array}$ & $\begin{array}{l}.16 \\
.19\end{array}$ & $\begin{array}{l}21 / 42 \\
24 / 27^{*}\end{array}$ \\
\hline
\end{tabular}

Note-A very few subjects failed to respond to all items on the recognition tests. As a result, the total number of items for a given item type in a given group does not always equal a multiple of $12 . \quad * p<.05 . \quad+\# O<P=$ number of subjects with observed $R F$ lower than predicted $R F$ out of the total number of subjects with nonzero cued recall scores. 
just described, we followed the lead of Muter and divided the data from these items into quartiles based on the overall recognition rates for the individual items. The observed and predicted quartile RF rates were $.70, .51, .42, .20$, and $.69, .50, .39, .21$, respectively (all ps $>.20$ ). These quartile data nicely replicate Muter's quartile data. However, as was pointed out earlier, when Muter's data were collapsed across quartiles, the observed RF rates were significantly lower than predicted. The data in Table 3 show this was not so in the present experiment. Thus, both our quartile and overall data converge and agree with Muter's conclusion that semantic RF of nonstudied famous names is well predicted by the TWF. Second, consider the RF rate in the semantic memory test for those famous names that were episodically encoded prior to the semantic recognition and cued recall tests. Although this prior episodic encoding raised semantic recognition hit rates above those observed for famous names not given this prior episodic encoding and raised them up to the level of correct cued recall performance (see Table 2), the observed RF rate for the famous names from the study list still did not deviate significantly from the TWF. Third, for the episodic group, the observed RF rate for the famous names from the study list did not deviate significantly from the TWF, whereas the observed RF rate for the nonfamous names from the study list were lower than it predicted.

\section{Nonname Tests}

For nonname tests, false alarms and cued recall intrusions were false positive recognitions and intrusions of nonnames not from the study list. For recognition, separate false alarm rates were computed for those lures associated with target items that had been studied in the related and unrelated pairs, respectively.

Overall cued recall and recognition performance. Because the only difference in the treatment of the episodic and semantic groups was in the type of name recognition test (semantic vs. episodic) that intervened between their nonname recognition and nonname cued recall tests, there is little reason, other than sampling error, to expect a difference in performance between the two groups. Since we did in some cases obtain performance differences for the episodic and semantic groups (see top portions of Tables 4 and 5), we decided to conduct an exact replication of the present experiment up through the nonname cued recall test. (Because the final, name cued recall test was different from that of the present experiment, the data from the name items in this replication are reported elsewhere; see Payne \& Neely, in press.) The top and bottom portions of Table 4 contain the recognition and cued recall performance on the nonname items for the present experiment and the replication experiment, respectively.

Recognition hit rates and correct cued recall rates were analyzed using a 2 (experiment: present vs. replica- tion) by 2 (group: semantic vs. episodic) by 2 (list: A vs. B) by 2 (item type: related vs. unrelated) by 2 (retention test: correct cued recall vs. recognition hit rate) mixed-factor analysis of variance. Although the episodic groups' performance was, averaged across experiments, superior to the semantic groups' performance $[\mathrm{F}(1,170)=3.9, \mathrm{MSe}=.089]$, there was also a significant Experiment by Group interaction $[F(1,170)$ $=8.1, \mathrm{MSe}=.089]$. The nature of this interaction was that whereas the episodic group did better than the semantic group in the present experiment, the opposite was the case in the replication experiment. Performance was better when the targets came from weakly related pairs rather than unrelated pairs $[F(1,170)=123.2$, $\mathrm{MSe}=.018]$, although the magnitude of this relatedness effect was larger for one list than for the other list $[F(1,170)=13.0, \mathrm{MSe}=.018$, for the List by Item Type interaction]. Recognition hit rates were higher than correct cued recall rates $[F(1,170)=399.2, \mathrm{MSe}=.032]$. However, there was also a significant Experiment by Group by Retention Test interaction $[F(1,170)=7.2$, $\mathrm{MSe}=.032]$, the nature of which was that recognition was equivalent in all four groups (formed by the factorial combination of two experiments and two groups), whereas in the present experiment recall was better for the episodic group than for the semantic group, with the opposite being the case for the replication experiment. Despite this interaction, recognition was superior to recall in both groups in both experiments.

Of central importance is the fact that the relatedness effect was much larger for recall than for recognition $[\mathrm{F}(1,170)=121.3, \mathrm{MSe}=.013]$. Specifically, recall of targets from related pairs was $20.6 \%$ greater than recall of targets from unrelated pairs, whereas recognition hit rates for targets from related pairs was only $1.8 \%$ greater than recognition hit rates for targets from unrelated pairs. This item Type by Retention Test interaction replicates the results of the episodic groups'

Table 4

Proportions of Recognition Hits, False Alarms, Correct Cued

Recall, and Cued Recall Intrusions for the Nonname Items

\begin{tabular}{lcccc} 
Pair Type & $\begin{array}{c}\text { Recognition } \\
\text { Hits }\end{array}$ & $\begin{array}{c}\text { False } \\
\text { Alarms }\end{array}$ & $\begin{array}{c}\text { Correct } \\
\text { Cued } \\
\text { Recall }\end{array}$ & $\begin{array}{c}\text { Cued } \\
\text { Recall } \\
\text { Intrusions }\end{array}$ \\
\hline Related & \multicolumn{4}{c}{ Semantic Group } \\
Unrelated & .80 & .14 & .67 & .05 \\
& .79 & .12 & .48 & .07 \\
Related & \multicolumn{5}{c}{ Episodic Group } \\
Unrelated & .75 & .19 & .52 & .07 \\
& .72 & .17 & .33 & .09 \\
Related & \multicolumn{5}{c}{ Semantic Group (Replication) } \\
Unrelated & .78 & .15 & .57 & .07 \\
& .79 & .16 & .40 & .07 \\
Related & \multicolumn{5}{c}{ Episodic Group (Replication) } \\
Unrelated & .79 & .15 & .67 & .04 \\
C & .76 & .13 & .40 & .07 \\
\hline
\end{tabular}


Table 5

A 2 by 2 Classification of the Recall and Recognition of the Name Items, Along With the Aggregate and Individual Subject Observed and Predicted Recognition Failure (RF) Rates

\begin{tabular}{|c|c|c|c|c|c|c|c|c|c|}
\hline \multirow[b]{2}{*}{ Pair Type } & \multicolumn{2}{|c|}{ Recognized } & \multicolumn{2}{|c|}{ Not Recognized } & \multicolumn{2}{|c|}{ Aggregate Data } & \multicolumn{2}{|c|}{ Individual Subject Data } & \multirow[b]{2}{*}{$\# \mathrm{O}<\mathrm{P}_{\ddagger}$} \\
\hline & Recalled & $\begin{array}{c}\text { Not } \\
\text { Recalled }\end{array}$ & Recalled & $\begin{array}{c}\text { Not } \\
\text { Recalled }\end{array}$ & $\begin{array}{c}\text { Observed } \\
\text { RF }\end{array}$ & $\begin{array}{c}\text { Predicted } \\
\text { RF }\end{array}$ & $\begin{array}{c}\text { Observed } \\
\text { RF }\end{array}$ & $\begin{array}{l}\text { Predicted } \\
\text { RF }\end{array}$ & \\
\hline & \multicolumn{9}{|c|}{ Semantic Group $(N=49)$} \\
\hline & 342 & 129 & 51 & 63 & .13 & .12 & .14 & .13 & $15 / 43$ \\
\hline \multirow[t]{2}{*}{ Unrelated } & 251 & 211 & 28 & 94 & .10 & .13 & .13 & .14 & $22 / 41$ \\
\hline & \multicolumn{9}{|c|}{ Episodic Group $(\mathrm{N}=47)$} \\
\hline \multirow{3}{*}{$\begin{array}{l}\text { Related } \\
\text { Unrelated }\end{array}$} & 262 & 159 & 29 & 113 & $.10^{*}$ & .16 & .10 & .17 & $29 / 43 *$ \\
\hline & 163 & 240 & 19 & 139 & $.10^{*}$ & .18 & .16 & .20 & $26 / 38^{*}$ \\
\hline & \multicolumn{9}{|c|}{ Semantic Group (Replication: $N=38$ ) } \\
\hline \multirow{3}{*}{$\begin{array}{l}\text { Related } \\
\text { Unrelated }\end{array}$} & 232 & 128 & 31 & 65 & .12 & .13 & .13 & .13 & $18 / 36$ \\
\hline & 159 & 195 & 22 & 78 & .12 & .13 & .15 & .15 & $20 / 32$ \\
\hline & \multicolumn{9}{|c|}{ Episodic Group (Replication: N $=44$ ) } \\
\hline \multirow{3}{*}{$\begin{array}{l}\text { Related } \\
\text { Unrelated }\end{array}$} & 314 & 136 & 57 & 54 & $.15^{*}$ & .12 & .16 & .13 & $17 / 38$ \\
\hline & 179 & 242 & 38 & 103 & .18 & .16 & .16 & .17 & $20 / 35$ \\
\hline & \multicolumn{9}{|c|}{ All Groups Combined } \\
\hline Related & 1152 & 535 & 168 & 295 & .13 & .13 & .13 & .14 & $79 / 160$ \\
\hline Unrelated & 752 & 898 & 108 & 414 & $.13 \dagger$ & .15 & .15 & .16 & $88 / 146^{*}$ \\
\hline
\end{tabular}

Note $-A$ very few subjects failed to respond to all items on the recognition tests. As a result, the total number of items for a given item type in a given group does not always equal a multiple of $12 . \quad{ }^{*} p<.05$. $\quad$ t.05 $<p<.10$. $¥ \# 0<P=$ number of subjects with observed $R F$ lower than predicted $R F$ out of the total number of subjects with nonzero cued recall scores.

performance on the name tests and Wiseman and Tulving's (1976) results. However, as with the episodic groups' name tests, the results of the nonname tests also fail to replicate Wiseman and Tulving's finding of cued recall performance exceeding overall recognition performance for targets from related word pairs. A significant List by Item Type by Retention Test interaction $[F(1,170)=$ $15.4, \mathrm{MSe}=.013 \mathrm{]}$ merely indicated that the greater effect of relatedness on recall than on recognition performance was larger for one list than for the other list.

Recognition failure. The 2 by 2 (recalled/not recalled by recognized/not recognized) contingency tables for the nonname items from the present experiment and the replication experiment are presented in Table 5. As can be seen in the top portion of Table 5 , in the present experiment in the semantic group, the observed RF rates for the targets from both the unrelated and weakly related pairs were not significantly different from their predicted values, whereas in the episodic group, both were significantly lower than predicted. However, as can be seen in the lower portion of Table 5, RF of nonname items from the related pairs in the replication was accurately predicted by the TWF in both the episodic and semantic groups. Since RF of targets from the related pairs in the episodic replication group was higher than predicted, not lower than predicted as it was in the first episodic group, it seems safe to conclude that in the first episodic group the deviation of the observed RF rates from the TWF for the targets from the related nonname pairs was a sampling error. Indeed, as can be seen in the next-to-last row in Table 5, averaged across all four groups, RF of targets from related nonname pairs was predicted almost perfectly by the TWF, a result that has been obtained time and time again (see Flexser \& Tulving, 1978).

Although the deviation of the observed from the predicted RF rates for targets from the unrelated nonname pairs was statistically significant only for the original episodic group, RF of these targets was lower than predicted in three of the four groups for the aggregate data. Also, in all four groups, more than half of the subjects had RF rates lower than predicted for these targets. Indeed, when averaged across all four groups, RF of targets from unrelated nonname pairs was significantly lower than the TWF predicted. Although this result is in accord with the RF data obtained in the episodic memory test for the unrelated nonfamous names from the study list, it is incongruent with Wiseman and Tulving's (1976) finding that the TWF accurately predicted RF of targets from unrelated pairs.

\section{GENERAL DISCUSSION}

In showing that the TWF successfully predicts RF of famous names whether they are tested in an episodic or a semantic memory test and, in the case of the semantic memory test, whether or not they have been recently episodically encoded, the present data are congruent with Muter's (1978) conclusion that RF is a semantic as well as an episodic memory phenomenon. Hence, the success of the TWF's characterization of RF appears not to depend on the "goodness" of a recent episodic encod- 
ing, as Flexser and Tulving (1978, p. 159) have argued; nor does the mere existence of RF depend on the formation of "unique" episodic memory traces, as Kintsch (1974, pp. 77.82) and Watkins and Tulving (1975, p. 6) have argued. Consequently, these theorists' assumptions about RF must be modified to permit RF even under conditions in which there is no opportunity for recently stored episodic information to influence retrieval, which are the conditions that occurred in Muter's (1978) experiment and for the nonstudied famous names in our semantic memory test.

If one considers famous and nonfamous names to be related and unrelated cue-target pairs, respectively, the data from both our name and nonname items demon. strate that RF of targets from "related" pairs are well predicted by the TWF, whereas RF of targets from "unrelated" pairs are significantly lower than predicted. Although this cue-target relatedness effect on episodic $\mathrm{RF}$ occurs for both word pairs and name pairs, it conflicts with Wiseman and Tulving's (1976) finding that the TWF accurately predicts RF rates for targets from unrelated as well as weakly related word pairs. Because we and Wiseman and Tulving (1976) used the same procedures and word pool to generate our unrelated pairs, a difference in materials cannot explain the discrepancy between our and their results. However, since our subjects studied the unrelated word pairs in the same list with weakly related word pairs and strongly related famous name pairs, they may have used an encoding strategy for the unrelated pairs different from the one they would have used had they studied only unrelated word pairs, as did Wiseman and Tulving's subjects. This speculation is congruent with results reported by Begg (1979) and by Gardiner and Tulving (1980) showing that exactly the same cue-target pair will yield RF rates that fall on or off the TWF depending on whether or not subjects tried to integrate the items in the pair during study. It seems, then, that the success of the TWF in predicting RF in episodic memory tests may not be determined so much by the semantic relatedness of the cue-target pairs as by the manner in which the cue-target pairs have been recently episodically encoded.

The fact that RF of famous names was equally well predicted by the TWF regardless of whether they were tested in an episodic or a semantic memory test and regardless of whether or not they were recently episodically encoded might be taken by some as evidence against the psychological reality of the episodic-semantic memory distinction (cf. Anderson \& Ross, 1980, p. 446). But because not even the staunchest supporter of this distinction would argue that every variable should have different effects in episodic and semantic memory tasks, it would be premature to embrace or reject the distinction on the basis of our results alone, particularly since they are incongruent with Carroll and Kirsner's (1982) finding that episodic memory retrieval is more affected than is semantic memory retrieval by contextual reinstatement of a recently "studied" episode. ${ }^{4}$ Thus, the ultimate resolution of whether the episodic-semantic distinction is psychologically valid must await the results from future experiments directly comparing a broad range of episodic and semantic memory phenomena under conditions that control for all variables other than the instructions given to distinguish the episodic and semantic memory tests. We believe these controls should be routinely employed, despite our finding that the accuracy of the TWF's predictions for RF of famous names in our semantic memory test did not depend on whether or not these names had been recently encoded. We believe this because it may be that recent episodic encoding will, through priming, differentially affect the dependent variables of interest in episodic and semantic memory tasks other than the ones we employed here (cf. Tulving, Schachter, \& Stark, 1982).

Of course, a critic may claim that in equating episodic and semantic memory tests on the episodic encoding that has preceded them, one necessarily renders the semantic memory test an "impure" measure of semantic memory. We have three responses to this. First, we agree that prior episodic input can render a semantic memory test "impure." But this contamination occurs only if episodic information can help determine what the correct response to an item is in the semantic memory test. Thus, the contamination can be avoided by having the correct response to an item in the semantic memory test be uncorrelated with whether or not that item has been previously studied in the experimental context, as was so in the present experiment. Second, episodic input prior to the semantic memory test would presumably leave semantic memory unaffected, since Tulving (1972, p. 386) has anuged that "retrieval of information from the [semantic] system leaves its contents unchanged, although any act of retrieval constitutes an input into episodic memory." Third, and perhaps most important, in defining whether a test is an episodic or a semantic memory test, Tulving did not say that to qualify as a semantic memory test the test items must not have been recently episodically encoded in the experimental context. Rather, Tulving (1972, p. 386) said that "the assignment of a task to one or the other category depends upon the kind of memory query addressed to the person, the exact nature of the information to be retrieved, or the nature of the memory claim made about the retrieved information by the person retrieving it." Hence, we maintain that unambiguous inferences about the episodic-semantic memory distinction can be drawn from direct comparisons of episodic and semantic memory phenomena only if the semantic and episodic memory tests are equated on all variables (including recent episodic input of the test items) except the instructions necessary to distinguish them.

\section{REFERENCES}

Anderson, J. R., \& Ross, B. H. Evidence against a semanticepisodic distinction. Journal of Experimental Psychology: Human Learning and Memory, 1980, 6, 441-465.

Atrinson, R. C., Herrmann, D. J., \& Wegcourt, K. T. Search processes in recognition memory. In R. L. Solso (Ed.). Theories 
in cognitive psychology: The Loyola Symposium. Potomac, Md: Erlbaum, 1974.

Bartlino, C. A., \& Thompson, C. P. Encoding specificity: Retrieval asymmetry in the recognition failure paradigm. Journal of Experimental Psychology: Human Learning and Memory, 1977, 3, 690-700.

BEga, I. Trace loss and the recognition failure of unrecalled words. Memory \& Cognition, 1979, 7, 113-123.

Carroll, M., \& Kirsner, K. Context and repetition effects in lexical decision and recognition memory. Journal of Verbal Learning and Verbal Behavior, 1982, 21, 55-69.

Flexser, A. J., \& Tulving, E. Retrieval independence and recall. Psychological Review, 1978, 85, 153-171.

Gardiner, J. M., \& Tulvina, E. Exceptions to recognition failure of recallable words. Journal of Verbal Learning and Verbal Behavior, 1980, 19, 194-209.

Herrmann, D. J., \& Harwood, J. R. More evidence for the existence of separate semantic and episodic stores in long-term memory. Journal of Experimental Psychology: Human Learning and Memory, 1980, 6, 467-478.

KINTsch, W. The representation of meaning in memory. Hillsdale, N.J: Erlbaum, 1974

McCloskey, M., \& Santee, J. Are episodic memory and semantic memory distinct systems? Journal of Experimental Psychology: Human Learning and Memory, 1981, 7, 66-71.

McKoon, G., \& RAtchifF, R. Priming in episodic and semantic memory. Journal of Verbal Learning and Verbal Behavior, $1979,18,463-480$.

Muten, P. Recognition failure of recallable words in semantic memory. Memory \& Cognition, 1978, 6, 9-12.

PAyne, D. G., \& NeEly, J. H. Recognition failure of recallable famous names in a hybrid semantic/episodic memory task. Bulletin of the Psychonomic Society, in press.

Shoren, E. J., Wescourt, K. T., \& Smith, E. E. Sentence verification, sentence recognition, and the semantic-episodic distinction. Journal of Experimental Psychology: Human Learning and Memory, 1978, 4, 304-317.

Tulving, E. Episodic and semantic memory. In E. Tulving \& W. Donaldson (Eds.), Organization of memory. New York: Academic Press, 1972.

Tulvina, E. Ecphoric processes in recall and recognition. In J. Brown (Ed.), Recall and recognition. London: Wiley, 1976.

Tulving, E., Schacter, D. L., \& Stark, H. A. Priming effects in word-fragment completion are independent of recognition memory. Journal of Experimental Psychology: Learning, Memory, and Cognition, 1982, 8, 336-342.
Tulving, E., \& Thomson, D. M. Encoding specificity and retrieval processes in episodic memory. Psychological Review, $1973,80,352-373$

Tulvina, E., \& Wiseman, S. Relation between recognition and recognition failure of recallable words. Bulletin of the Psychonomic Society, 1975, 6, 79-82.

Watkins, M. J., \& Tulvina, E. Episodic memory: When recognition fails. Journal of Experimental Psychology: General, 1975, 104, 5-29.

Webster's New Collegiate Dictionary. Springfield, Mass: Merriam, 1976.

Wiseman, S., \& Tulving, E. Encoding specificity: Relation between recall superiority and recognition failure. Journal of Experimental Psychology: Human Learning and Memory, 1976, 2, 349-361.

\section{NOTES}

1. With hits defined as $\mathrm{Y}$ responses (to target items) given a confidence rating of 3 , overall recognition rates were greatly reduced but the accuracy or inaccuracy of the TWF's predictions were not affected. Hence, we present only data based on the more lenient criterion of a confidence rating of 2 .

2. Due to the computerized statistical package we employed whenever the number of words both recalled and recognized was less than or equal to 100 , the binomial equation was used. Otherwise, the normal approximation to the binomial distribution was used with $z=$ (observed RF - predicted RF) $\div$ $\sqrt{[(\text { predicted RF } \times(1-\text { predicted } R F)) \div N]}$, where $N$ is the number of recalled words.

3. We thank Arthur Glenberg for suggesting this more appropriate analysis.

4. Our results are, however, congruent with McKoon and Ratcliff's (1979) finding that episodic contextual reinstatement has a similar effect on retrieval from episodic and semantic memory. In McKoon and Ratcliff's (1979) experiment and the present experiment, prior to the episodic and semantic memory tests, subjects studied the words in the context-target pair in anticipation of a cued recall test, whereas in Carroll and Kirsner's (1982) experiment, they merely made lexical decisions about them and hence had no reason to expect an episodic memory test. Thus, equivalent episodic context effects in episodic and semantic memory tests may depend on subjects' studying context-target pairs in anticipation of an episodic cued recall test, as they did in McKoon and Ratcliff's and our experiments.

Appendix

Famous and Nonfamous Name Items Used in the Experiment

\section{Target}

Arnold

Berlin

Bryan*

Burke*

Burr

Cody

Cooper*

Davis*

Doyle*

Ericson

Foster*

Franklin*

Henry

London*

Morse

Nash

Reed
Cues

Famous Names

General in American Revolutionary War: Benedict

U.S. composer (White Christmas): Irving

U.S. politician and religious leader: William Jennings

British 18th-century political thinker: Edmund

Third vice president; fought duel with Alexander Hamilton: Aaron

American scout and Indian fighter: Buffalo Bill

Author of Last of the Mohicans: James Fenimore

President of the Confederacy during U.S. Civil War: Jefferson

Author of Sherlock Holmes stories: Arthur Conan

Norwegian mariner and reputed discoverer of America: Leif

U.S, song writer (Swanee River, Old Black Joe): Stephen

U.S. statesman and inventor: Benjamin

American orator, "Give me liberty or give me death": Patrick

U.S. author of Call of the Wild and The Sea Wolf: Jack

American inventor of telegraphic code: Samuel

American poet and humorist: Ogden

American Army surgeon: Walter 


\begin{tabular}{|c|c|}
\hline Ross* & Maker of U.S. flag: Betsy \\
\hline Scott & American slave; central figure in U.S. lawsuit: Dred \\
\hline Shaw & British author and socialist; Pygmalian: George Bernard \\
\hline Spencer* & English 19th-century philosopher: Herbert \\
\hline Thomas* & Welsh poet: Dylan \\
\hline Whitney* & Inventor of the cotton gin: Eli \\
\hline \multirow[t]{2}{*}{ Young* } & U.S. Mormon leader: Brigham \\
\hline & Nonfamous Names \\
\hline Andrews & Physicist and winner of Nobel Prize: Douglas \\
\hline Becker & Harvard president; coined term Ivy League: Jay \\
\hline Collins & U.S. jazz composer and pianist: Ronald \\
\hline Conway* & British philosopher and essayist: Edwin \\
\hline Foley* & Leader of alcohol prohibition movement: Eileen \\
\hline Good* & 19th-century U.S. textile merchant: Frank Hughes \\
\hline Hess & U.S. World War I general: Ralph Alan \\
\hline Howell & American explorer, fur trader, and scout: Roger \\
\hline Jacobson & Swedish political satirst: Albert \\
\hline Kane & American playwright and poet: Michael \\
\hline Kasper & 20th-century illustrator for Saturday Evening Post: Adam \\
\hline Klein & Canadian sexologist and psychologist: Howard \\
\hline Lane* & Founder of National Georgraphic Society: Burton \\
\hline Link & Founder of U.S. Pony Express: Donald \\
\hline Lyons & Australian composer; Down Under is On Top: Oscar \\
\hline Mack & Black American social reformer: Clarence \\
\hline Moore & Military surgeon and discoverer of vaccines: Eugene \\
\hline Novack & Polish immigrant; helped develop atomic bomb: Lewis \\
\hline Peters & American inventor of fluorescent lighting: Melvin \\
\hline Phillips & British religious and social reformer: Earl Paul \\
\hline Pierce $\dagger$ & U.S. 18th-century presidential candidate: Leonard \\
\hline Reilly & British song writer (London Moon, The Queen's Palace): Emmet \\
\hline Shea & Pioneer in diesel engine development: Morgan Curtis \\
\hline Tucker & Irish author and historian: Anthony \\
\hline
\end{tabular}

*These names were used by Muter (1978). TDue to an oversight, Pierce was selected as a nonfamous name. (Franklin Pierce was the 14th U.S. president.) It is interesting that even though the person who made up the character descriptions claims to recognize Franklin Pierce as a famous name, the name Pierce alone was not recognized as famous (and was overlooked when Pierce was looked up in the dictionary). Despite the fact that Pierce alone was not recognized as being famous, it seems unlikely that it was mere chance that the "fictitious" description that was generated pertained to a U.S. president. Apparently, for this person, the name Pierce was associated with "president," but only the full name Franklin Pierce could be recognized as a particular U.S. president. 